\title{
Subthreshold Amyloid Predicts Tau Deposition in Aging
}

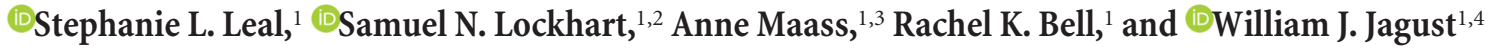 \\ ${ }^{1}$ Helen Wills Neuroscience Institute, University of California, Berkeley, California 94720, ${ }^{2}$ Department of Internal Medicine, Division of Gerontology and \\ Geriatric Medicine, Wake Forest School of Medicine, Winston-Salem, North Carolina 27157, ${ }^{3}$ German Center for Neurodegenerative Diseases, Magdeburg, \\ Germany 39120, and ${ }^{4}$ Molecular Biophysics and Integrated Bioimaging, Lawrence Berkeley National Laboratory, Berkeley, California 94720
}

Current approaches to the early detection of Alzheimer's disease (AD) rely upon classifying individuals as "positive" or "negative" for biomarkers related to the core pathology of $\beta$-amyloid $(\mathrm{A} \beta)$. However, the accumulation of $\mathrm{A} \beta$ begins slowly, years before biomarkers become abnormal. We used longitudinal $\left[{ }^{11} \mathrm{C}\right]$ Pittsburgh Compound B PET scanning and neuropsychological assessment to investigate the earliest changes in AD pathology and how it affects memory in cognitively normal older humans $(N=71$; mean age 75 years; $35 \%$ male). We used $\left[{ }^{18} \mathrm{~F}\right] \mathrm{AV}-1451$ PET scanning at the end of the observation period to measure subsequent tau deposition in a subset of our sample $(N=37)$. We found evidence for an inverted-U relationship between baseline $\mathrm{A} \beta$ levels and $\mathrm{A} \beta$ slope in asymptomatic older adults, suggesting a slowing of $\mathrm{A} \beta$ accumulation even in cognitively normal adults. In participants who were nominally amyloid negative, both the rate of amyloid accumulation and the baseline levels of $\mathrm{A} \beta$ predicted early tau deposition in cortical Braak regions associated with $\mathrm{AD}$. Amyloid measures were only sensitive to memory decline as baseline levels of $\mathrm{A} \beta$ increased, suggesting that pathological accumulation occurs before impacting memory. These findings support the necessity of early intervention with amyloid-lowering therapies even in those who are amyloid negative.

Key words: aging; amyloid; memory; PET; preclinical; tau

\section{Significance Statement}

The progressive nature of Alzheimer's disease $(\mathrm{AD})$ necessitates the earliest possible detection of pathological or cognitive change if disease progression is to be slowed. We examined cognitively normal older adults in whom AD pathology is starting to develop, with the goal of early detection of $\mathrm{AD}$ pathology or cognitive changes. We found amyloid measures to be sensitive early on in predicting subsequent early tau deposition. Further, it appears that rates of amyloid accumulation already begin to slow in preclinical $\mathrm{AD}$, suggesting that it is a relatively late stage of $\mathrm{AD}$ progression. Thus, it is crucial to examine older adults early, before amyloid levels have saturated, to intervene to slow disease progression.

\section{Introduction}

Alzheimer's disease $(\mathrm{AD})$ is characterized pathologically by the presence of $\beta$-amyloid (A $\beta$ ) plaques and neurofibrillary tau tangles, and clinically by the early impairment of episodic memory (Welsh et al., 1992). Several pathologic staging schemes for A $\beta$

Received Feb. 21, 2018; revised March 20, 2018; accepted March 27, 2018.

Author contributions: S.L.L. and W.J.J. designed research; S.L.L., S.N.L., A.M., and W.J.J. performed research;

S.L.L., S.N.L., A.M., and R.K.B. analyzed data; S.L.L. wrote the paper.

This research was supported by National Institute of Aging of the National Institutes of Health Grants F32-AG054116 and R01-AG-034570 and by the Tau Consortium. Avid Radiopharmaceuticals enabled the use of the $\left[{ }^{18} \mathrm{~F}\right]$ AV-1451 tracer, but did not provide direct funding and were not involved in data analysis or interpretation. We thank Suzanne Baker, Taylor Mellinger, and Kaitlin Swinnerton for assistance with data collection and processing, and Tessa Harrison and Joe Winer for helpful discussion regarding memory measures. We also thank the participants of the Berkeley Aging Cohort Study who participated in this study.

W.J.J. has served as a consultant to Bioclinica, Genentech, Novartis, and Biogen. The authors declare no other competing financial interests.

Correspondence should be addressed to Dr. Stephanie L. Leal, Helen Wills Neuroscience Institute, University of California, Berkeley, 132 Barker Hall, Berkeley CA, 94720. E-mail: stephanieleal@berkeley.edu.

DOI:10.1523/JNEUROSCI.0485-18.2018

Copyright $\odot 2018$ the authors $\quad 0270-6474 / 18 / 384482-08 \$ 15.00 / 0$ deposition have been adopted and generally describe a broad distribution of plaque pathology throughout cerebral cortex (Mirra et al., 1991; Braak and Braak, 1997; Thal et al., 2000). Autopsy studies suggest, however, that tau deposition follows Braak staging, beginning more focally in the medial temporal lobes, spreading through inferolateral temporal lobes, and finally to diffuse cortical regions (Braak and Braak, 1997). Neuropathological data suggest that $\mathrm{A} \beta$ may produce or exacerbate neurofibrillary tau aggregation (Price and Morris, 1999; Thal et al., 2002).

Examining the longitudinal time course of the relationship between $\mathrm{A} \beta$ and tau in vivo has become possible with the development of $\left[{ }^{11} \mathrm{C}\right]$ Pittsburgh Compound B (PIB) PET imaging $(\mathrm{A} \beta)$ and $\left[{ }^{18} \mathrm{~F}\right] \mathrm{AV}-1451$ PET imaging (tau). Studies have found that widespread tau deposition occurs in the presence of neocortical $\mathrm{A} \beta$ and is associated with cognitive decline and progression to AD (Schöll et al., 2016; Pascoal et al., 2017). Failures of phase III clinical trials of anti-A $\beta$ therapies (Drachman, 2014) have raised the possibility that such trials begin too late, once the disease has exerted irreversible effects on the brain (Sperling et al., 
Table 1. Participant demographics, APOE $\varepsilon 4$ status, PIB, AV-1451, and change in cognition

\begin{tabular}{|c|c|c|c|c|c|c|c|}
\hline Variables & $\begin{array}{c}\text { All older } \\
\text { adults } \\
(N=71)\end{array}$ & $\begin{array}{c}<1.30 \mathrm{PIB} \\
\text { older adults } \\
(N=61)\end{array}$ & $\begin{array}{c}<1.07 \mathrm{PIB} \\
\text { older adults } \\
(N=51)\end{array}$ & $\begin{array}{l}\text { All with } \\
\text { AV-1451 } \\
(N=37)\end{array}$ & $\begin{array}{c}<1.30 \text { PIB } \\
\text { with AV-1451 } \\
\quad(N=33)\end{array}$ & $\begin{array}{c}<1.07 \mathrm{PIB} \\
\text { with AV-1451 } \\
\quad(N=27)\end{array}$ & Range \\
\hline $\mathrm{PIB}^{+}$(all time points), $N(\%)$ & $20(28)$ & $10(16)$ & $0(0)$ & $10(27)$ & $6(18)$ & $0(0)$ & \\
\hline $\mathrm{PIB}^{+}$converters $\left(\mathrm{PIB}^{-}\right.$to $\left.\mathrm{PIB}^{+}\right), N(\%)$ & $13(18)$ & $13(21)$ & $0(0)$ & $7(19)$ & $7(21)$ & $0(0)$ & \\
\hline PIB follow-up (years) & $4.5(2.2)$ & $4.8(2.4)$ & $4.5(2.2)$ & $4.8(2.4)$ & $5.3(2.5)$ & $4.8(2.4)$ & $1.1-9.3$ \\
\hline Cognitive testing follow-up (years) & $5.7(2.3)$ & $6.1(2.4)$ & $5.9(2.4)$ & $5.2(2.3)$ & $5.6(2.5)$ & $5.2(2.4)$ & $1.8-10.8$ \\
\hline Age (years) & $75.4(5.4)$ & $75.1(5.6)$ & $75.1(5.5)$ & $75.5(4.4)$ & $75.4(4.6)$ & $75.6(4.9)$ & $61-88$ \\
\hline Male sex, $\%$ & 35 & 36 & 36 & 41 & 39 & 41 & \\
\hline Years of education & $17(1.7)$ & $17(1.7)$ & $17.1(1.8)$ & $17(1.8)$ & $17.2(1.8)$ & $17.3(1.8)$ & $13-20$ \\
\hline$\% A P O E \& 4$ carriers & 30 & 22 & 22 & 32 & 24 & 22 & \\
\hline Baseline MMSE & $28.9(1.3)$ & $29.0(1.2)$ & $29.1(1.2)$ & $28.9(1.4)$ & $29.1(1.2)$ & $29.0(1.3)$ & $25-30$ \\
\hline Baseline PIB & $1.10(0.19)$ & $1.04(0.07)$ & $1.02(0.03)$ & $1.09(0.17)$ & $1.04(0.07)$ & $1.01(0.03)$ & $0.96-1.69$ \\
\hline$\Delta \mathrm{PIB}$ & $0.02(0.02)$ & $0.01(0.02)$ & $0.008(0.01)$ & $0.02(0.02)$ & $0.01(0.02)$ & $0.008(0.01)$ & -0.009 to 0.08 \\
\hline$\Delta$ Episodic Memory Composite & $-0.01(0.10)$ & $-0.002(0.09)$ & $0.01(0.09)$ & $0.005(0.10)$ & $0.012(0.10)$ & $0.025(0.11)$ & -0.20 to 0.27 \\
\hline AV-1451 SUVR in Braak stages I-II & & & & $1.30(0.21)$ & $1.26(0.18)$ & $1.27(0.19)$ & $0.94-1.88$ \\
\hline AV-1451 SUVR in Braak stages III-IV & & & & $1.22(0.11)$ & $1.20(0.09)$ & $1.20(0.09)$ & $1.03-1.48$ \\
\hline AV-1451 SUVR in Braak stages V-VI & & & & $1.18(0.09)$ & $1.17(0.09)$ & $1.17(0.09)$ & $1.01-1.33$ \\
\hline
\end{tabular}

Values are given as the mean (SD), unless otherwise noted. MMSE, Mini Mental State Exam. All participants had no contradictions to MRI; were living independently in the community; 5 cored $\geq 25$ on the MMSE; scored within age, education, and gender norms; and had no neurological or psychiatric illness, major medical illnesses, or medications that affect cognition. All participants provided blood samples that were analyzed for APOE polymorphisms using a standard protocol. Participants were dichotomized into carriers and noncarriers of the APOE $\varepsilon 4$ allele. AV-1451 scans were collected within 3 months of the participant's last PIB scan.

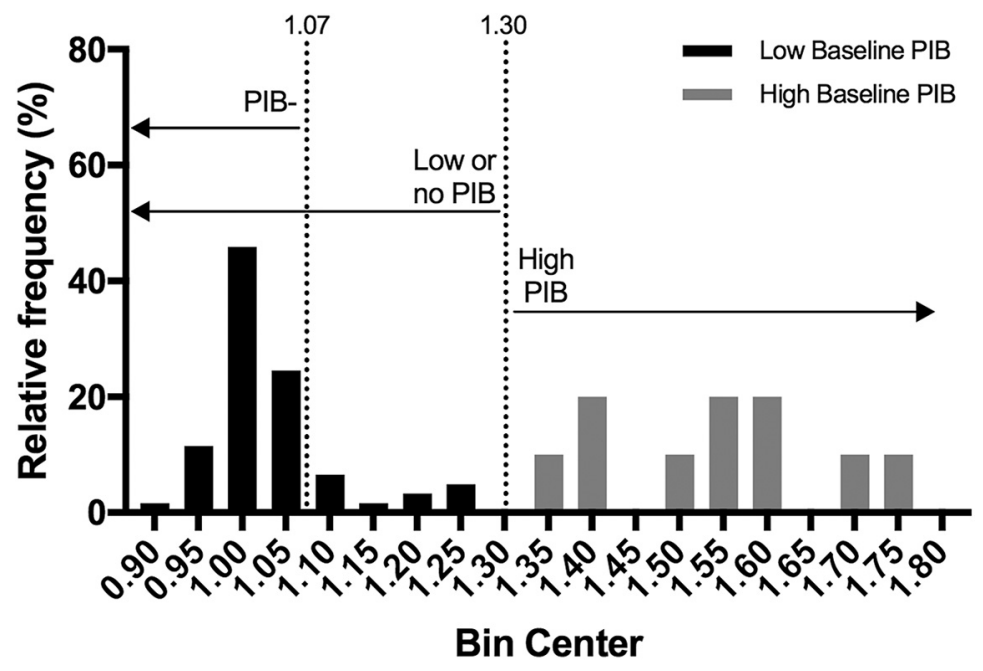

Figure 1. Relative frequency (\%) of participant's baseline PIB DVR. We predefined the number of clusters to two to determine a sensitive cutoff value between low and high baseline PIB levels, which was determined based on the point where the two clusters met but did not overlap. K-means clustering analyses yielded one cluster centered at the 1.54 baseline PIB DVR $(N=10)$, including participants with $\mathrm{a}>1.30$ PIB DVR and another cluster centered at the 1.03 baseline PIB DVR $(N=61)$, including participants with a $<1.30$ PIB DVR. The 1.30 threshold was based on this approach; the threshold for PIB positivity was 1.07 , as previously reported.

2011b). Cognitively normal individuals reaching a threshold for $\mathrm{A} \beta$ positivity (as measured via $\mathrm{A} \beta$ PET imaging or CSF assay) have been defined as having "preclinical AD" (Sperling et al., 2011b), are likely to be at risk for the development of AD (Vos et al., 2013; Donohue et al., 2017), and are thus potential targets of pharmacologic intervention before showing symptoms (Sperling et al., 2011b, 2014; Mullard, 2012).

Because individuals with $\mathrm{AD}$ have evidence of $\mathrm{A} \beta$ deposition decades before they are destined for symptoms (Bateman et al., 2012; Villemagne et al., 2013), the issue of exactly when $A \beta$ deposition begins to exert harmful neurological effects is crucial and also tractable with studies using imaging methods. Most studies have classified participants as "amyloid positive" or "amyloid negative"; while this is useful for categorizing an individual for a potential clinical trial or predicting decline, it results in considerable loss of information (Villeneuve et al., 2015) and neglects the potential importance of early $\mathrm{A} \beta$ deposition and accumulation in revealing disease mechanisms. Furthermore, the rate of change of $\mathrm{A} \beta$ deposition may not be linear over time, suggesting that there may be critical periods for intervention with an amyloid-lowering therapy (Jack et al., 2013b; Villemagne et al., 2013). These concepts are important in proposing interventions at the earliest possible stages of AD development.

In this study, we examined cognitively normal older adults who underwent longitudinal $\left[{ }^{11} \mathrm{C}\right]$ PIB imaging and neuropsychological assessment as well as a subset of individuals who also underwent $\left[{ }^{18} \mathrm{~F}\right] \mathrm{AV}-1451$ PET imaging at the end of the observation period to investigate the earliest stages of AD pathology. Further, we aimed to determine whether we can predict subsequent tau deposition and memory decline in cognitively normal older adults.

\section{Materials and Methods}

Participants. Seventy-one cognitively normal older adults underwent longitudinal $\left[{ }^{11} \mathrm{C}\right] \mathrm{PIB}$ PET imaging and cognitive testing as part of the Berkeley Aging Cohort Study (BACS). A subset of the participants also underwent $\left[{ }^{18} \mathrm{~F}\right] \mathrm{AV}$ 1451 PET scans at the end of the observation period (Table 1). All participants provided informed consent in accordance with the Institutional Review Boards of the University of California, Berkeley, and the Lawrence Berkeley National Laboratory (LBNL).

Defining PIB thresholds. PIB retention was dichotomized in two ways. First, participants were classified using a threshold previously defined in our laboratory [Villeneuve et al., 2015; cutoff $=1.07$ PIB distribution volume ratio (DVR)] to define $\mathrm{PIB}^{+}$and $\mathrm{PIB}^{-}$groups (at baseline). All cognitively normal older adults were also characterized by their PIB status across time $\left(\mathrm{PIB}^{-}, \mathrm{PIB}^{+}\right.$converter, or $\mathrm{PIB}^{+}$using a standard threshold for PIB positivity of 1.07 PIB DVR). Second, K-means clustering was performed on participants' baseline PIB DVR data (Fig. 1) to determine a threshold based on the point where the two clusters met but did not overlap (1.30 PIB DVR), which split participants into low or no PIB $\left(<1.30\right.$ and including $\left.\mathrm{PIB}^{-}\right)$, and high PIB $(>1.30)$ groups. Table 1 
summarizes the features of all participants and the subset who underwent AV-1451 PET imaging.

Neuropsychological testing. Participants received annual neuropsychological evaluations, with a maximum delay of 4 months between the first PIB scan and the closest testing session. The California Verbal Learning Test and the Wechsler Memory Scale-III Visual Reproduction Test were administered to assess episodic memory processing. We created a composite episodic memory score across these two tests, including both short and long delay intervals. We performed a $z$-score calculation for each measure using norms from a larger BACS sample $(N=158$, average age $74.1 \pm 5.7$ years, average education $16.7 \pm 2.0$ years, $38 \%$ male) and calculated the slope of the regression line to examine change in episodic memory performance over time $[\Delta V$ isual Reproduction I/II and California Verbal Learning Test: Immediate and Delayed Free Recall ( $\Delta$ Episodic Memory Composite)].

MRI acquisition. All participants underwent MRI scanning at LBNL on a 1.5 T Siemens Magnetom Avanto System with a 12-channel head coil run in triple mode (Mormino et al., 2012; Leal et al., 2017). A highresolution structural T1-weighted volumetric magnetization prepared rapid gradient echo scan was processed with FreeSurfer version 5.3 to derive regions of interest (ROIs) in each participant's native space using the atlas by Desikan et al. (2006) for PET tracer quantification. We also calculated the number of voxels in all of the FreeSurfer cortical ROIs at each PIB time point and calculated the slope with the number of cortical gray matter voxels and time of MRI scan to control for cortical gray matter changes over time.

PIB PET acquisition and processing. A detailed description of PIB PET acquisition has been published previously (Mormino et al., 2009). All PIB PET data were preprocessed using Statistical Parametric Mapping (SPM) version 12 software (http://www.fil.ion.ucl.ac.uk/spm/), summed, and realigned as previously reported (Leal et al., 2017; Marks et al., 2017). PIB DVR images were created using Logan graphical analysis with frames corresponding to 35-90 min after injection and a cerebellar gray matter reference region. Mean DVR values from frontal, parietal, temporal, and cingulate cortices were computed to serve as a global PIB index for all participants.

AV-1451 PET acquisition and processing. A detailed description of AV1451 PET acquisition has been published previously (Ossenkoppele et al., 2016; Schöll et al., 2016). AV-1451 scans were collected within 3 months of the participant's last PIB scan. AV-1451 standardized uptake value ratio (SUVR) images were created based on mean uptake over $80-100$ min postinjection (Shcherbinin et al., 2016; Baker et al., 2017; Wooten et al., 2017) normalized by mean inferior cerebellar gray matter uptake (Maass et al., 2017). SUVR images were coregistered and resliced to the structural MRI closest in time to AV-1451 PET scanning (mean delay, 2.3 months). Analyses based on a priori-defined ROIs were performed on AV-1451 SUVR images in native space after partial volume correction (PVC) using the Geometric Transfer Matrix approach (Rousset et al., 1998). We calculated a native-space weighted mean SUVR after PVC from three composite ROIs that correspond to the anatomical definitions of Braak stages I-II (transentorhinal), III-IV (inferolateral temporal), and V-VI (neocortical; Braak and Braak, 1997; Maass et al., 2017).

Statistical analysis. All statistical analyses were conducted in SPSS version 24 (IBM). Linear and quadratic regressions were performed to examine the relationship between baseline PIB levels and PIB slope. We used residual sum of squares and the Akaike information criterion (AIC) to compare which fitting approach matched the data best. PIB slope was calculated using the equation, $b=\Sigma(x-\bar{x} ; y-\bar{y}) / \Sigma(x-\bar{x})^{2}$, where $x$ corresponds to PIB DVR and $y$ corresponds to years since baseline PIB levels. We conducted a series of stepwise multiple linear regression models to predict subsequent tau deposition and memory decline, including baseline PIB levels, PIB slope, gray matter slope, APOE $\varepsilon 4$ status, age, sex, and education as predictors. Statistical values were considered significant at an $\alpha$ level of 0.05 to prevent type I error inflation.

\section{Results}

\section{Amyloid accumulation is slowing in cognitively normal} older adults

We examined the relationship between baseline $A \beta$ levels and the rate of change in $A \beta$ in all participants to determine how the rate of change in amyloid accumulation changes with increasing amyloid levels. Mean DVR values from frontal, parietal, temporal, and cingulate cortices were computed to serve as a global PIB index for all participants. PIB slope was calculated based on these PIB DVR values. It is important to note that a subset of participants had slightly negative PIB slopes, which we considered to be measurement noise and not a significant decrease in amyloid accumulation ( $N=9$; maximum decrease, -0.009$)$. Thus, we opted to include these individuals in our analysis, and they are considered to be "nonaccumulators." We tested both linear and quadratic relationships between the variables, with baseline PIB levels as the independent variable and PIB slope as the dependent variable (Fig. 2) across all participants (Table 1, demographics). We found a significant linear $\left(r_{(1,69)}^{2}=0.194, p<0.001\right)$ and quadratic relationship $\left(r_{(2,68)}^{2}=0.293, p<0.001\right)$ between the variables; however, the quadratic relationship was a better fit to the data according to both residual sum of squares (linear residual sum of squares $=0.021>$ quadratic residual sum of squares $=0.018$ ) and an AIC approach (quadratic relationship was the preferred model with a probability of $97 \%$ correct; linear AIC $=-41.99>$ quadratic AIC $=-377.35)$. We performed the same analysis after excluding nonaccumulators with negative PIB slopes to ensure they were not driving these relationships. Results remained the same (linear $r_{(1,54)}^{2}=0.157, p=0.002$; quadratic $\left.r_{(2,53)}^{2}=0.308, p<0.001\right]$. Thus, even in preclinical AD, higher baseline $A \beta$ levels are associated with decelerating $A \beta$ deposition, similar to what is seen in individuals with mild cognitive impairment or AD (Jack et al., 2013b; Villemagne et al., 2013).

\section{Amyloid measures predict tau deposition in cognitively normal older adults}

To investigate the earliest effects of amyloid measures on subsequent tau deposition, we examined the subset of individuals who underwent AV-1451 PET imaging at the end of the observation period. We then focused our analyses on those who would be classified as "amyloid negative" at baseline using a threshold previously defined in our laboratory (Villeneuve et al., 2015; $\mathrm{PIB}^{-}=$ $<1.07$ PIB DVR; Table 1, demographics). Even though these individuals are considered to be amyloid negative, we hypothesized 

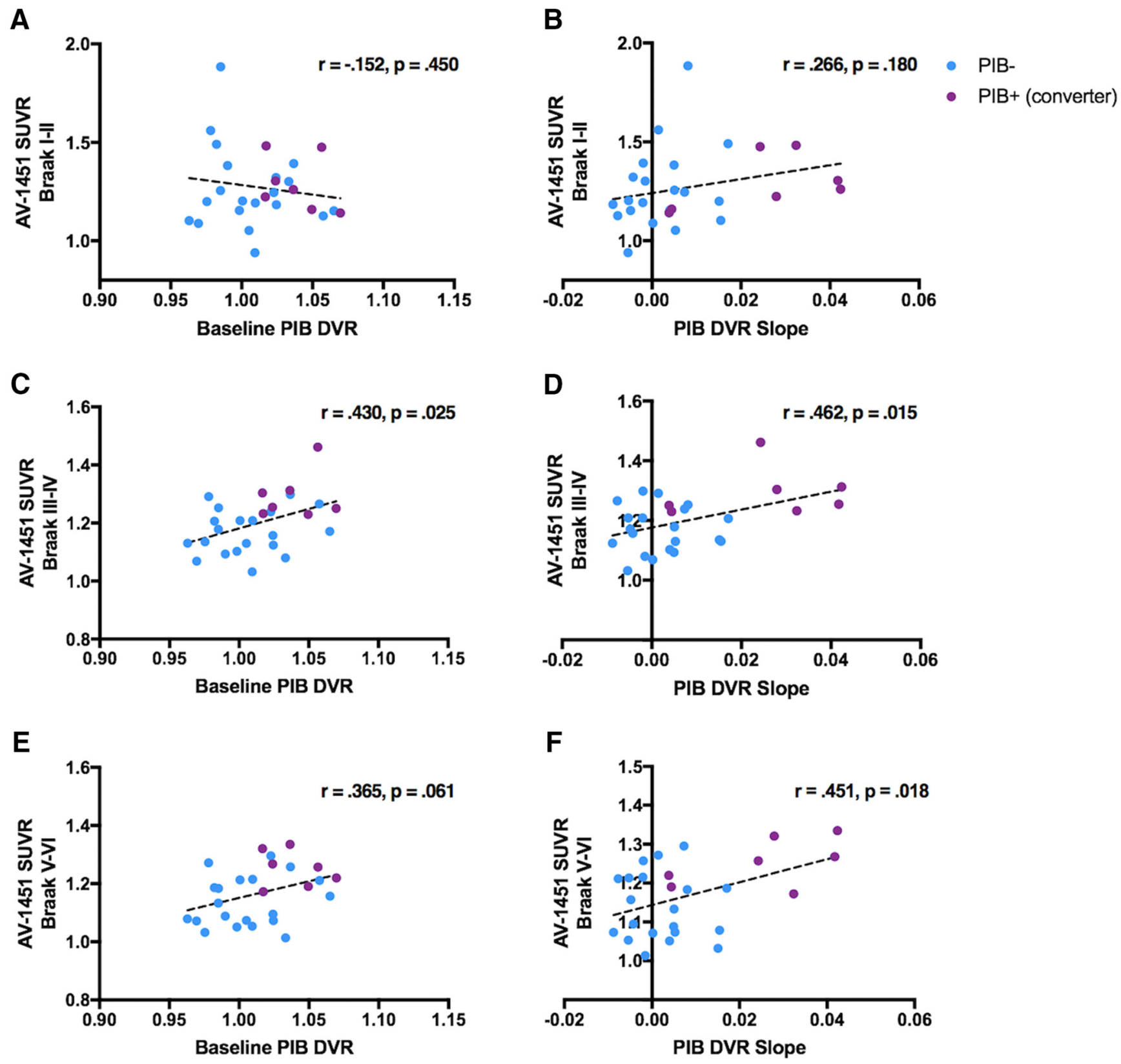

Figure 3. Relationship between PIB measures and AV-1451 uptake in Braak stages I-II, III-IV, and V-VI ROIs in PIB ${ }^{-}$individuals. Participants $(N=27)$ were identified as PIB ${ }^{-}($blue $)$and PIB ${ }^{+}$ converters (purple) based on a standard threshold of 1.07 PIB DVR. $A$, Correlation between baseline PIB DVR and AV-1451 uptake in Braak stages I-II in PIB ${ }^{-}$participants. B, Correlation between PIB DVR slope and AV-1451 uptake in Braak stages I-II in PIB ${ }^{-}$participants. C, Correlation between baseline PIB DVR and AV-1451 uptake in Braak stages III-IV in PIB ${ }^{-}$participants. D, Correlation

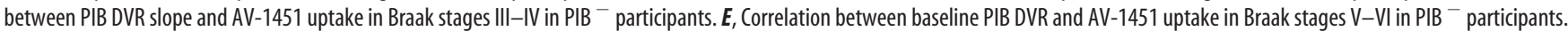
$\boldsymbol{F}$, Correlation between PIB DVR slope and AV-1451 uptake in Braak stages V-VI in PIB ${ }^{-}$participants.

that measuring amyloid using a continuous approach may reveal a biological significance for even low levels of amyloid in predicting early tau deposition and memory decline.

A stepwise linear regression in $\mathrm{PIB}^{-}$participants examined what variables best predicted AV-1451 uptake in Braak stages I-II, III-IV, and V-VI ROIs, including baseline PIB DVR levels, PIB DVR slope, gray matter slope, APOE $\varepsilon 4$ status, age (at the time of the AV-1451 scan), sex, education, and delay between AV-1451 scan and baseline PIB scan as predictors. For visualization of regression results, correlations between baseline PIB levels and PIB DVR slope with AV-1451 uptake in ROIs reflecting Braak stages I-II, III-IV, and V-VI in $\mathrm{PIB}^{-}$participants are shown in Figure 3. Clearly, baseline PIB levels and PIB slope are significantly associated with AV-1451 uptake in Braak stages III-IV and V-VI ROIs when examining the bivariate relationships between PIB measures and AV-1451 uptake. In predicting AV-1451 uptake in Braak stages I-II, we found that no predictors satisfied model entry criteria. However, PIB slope was the best predictor of AV-1451 uptake in Braak stages III-IV $\left(r_{(1,25)}^{2}=\right.$ 0.462, $\left.\beta=3.005, t=2.605, p=0.015, r^{2}=0.21\right)$ and V-VI $\left(r_{(1,25)}^{2}=0.451, \beta=2.944, t=2.530, p=0.018, r^{2}=0.18\right) . \mathrm{A}$ second model also included baseline PIB as a significant predictor of AV-1451 uptake in Braak stages III-IV $\left(\Delta r^{2}=0.20\right)$ and V-VI $\left(\Delta r^{2}=0.14\right)$, and a third model included APOE $\varepsilon 4$ status in predicting AV-1451 uptake in Braak stages III-IV $\left(\Delta r^{2}=0.09\right)$. These models suggest that baseline levels of amyloid, perhaps 

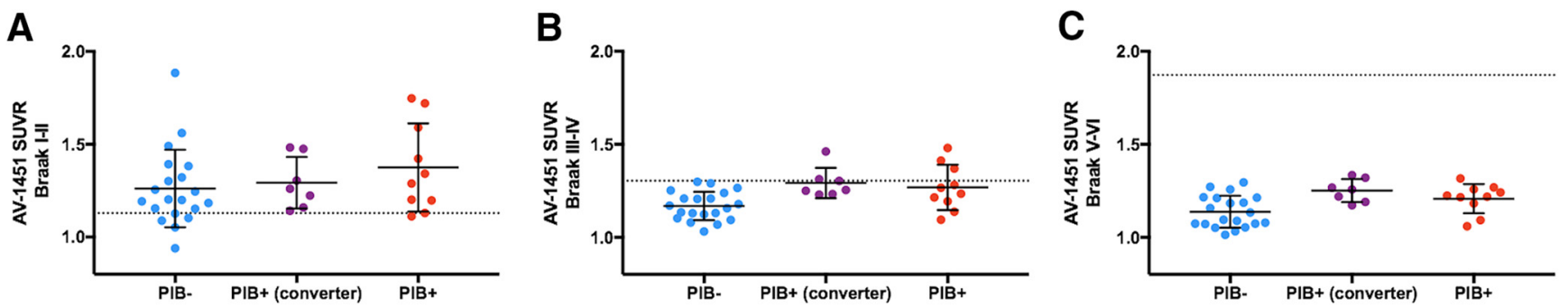

Figure 4. AV-1451 uptake in Braak stages I-II, III-IV, and V-VI regions. Participants were identified as PIB ${ }^{-}$(blue), PIB $^{+}$converters (purple), and PIB ${ }^{+}$based on a standard threshold of 1.07 PIB DVR. Dotted lines in each panel indicate the threshold for classification as meeting that Braak stage. A, AV-1451 SUVR uptake in Braak stages I-II regions, with most participants being classified as stages I-II (Braak stage I/II mean SUVR, >1.129). B, AV-1451 SUVR uptake in Braak stages III-IV regions, with five participants being classified as stages III-IV (Braak stage III/IV mean SUVR, >1.304). C, AV-1451 SUVR uptake in Braak stages V-VI regions, with no participants being classified as stage V-VI (Braak stage V/VI mean SUVR, >1.873).

being reflected by additionally including $A P O E \varepsilon 4$ status, are strong predictors of subsequent tau deposition in addition to PIB slope in the later Braak stage ROIs.

It is important to note that the AV-1451 levels in Braak stages V-VI are low and do not suggest these individuals would be classified as being in Braak stages V-VI, but rather, as others have noted, there is evidence that tau is beginning to deposit in widespread neocortical areas even in normal people who are amyloid negative (Lowe et al., 2018). Most cognitively normal individuals in the study are classified as being in Braak stages I-II (Fig. 4A), five in Braak stages III-IV (two PIB ${ }^{+}$converters and three PIB ${ }^{+}$; Fig. $4 B$ ) and no participants in Braak stages V-VI, as expected (Fig. 4C).

Next, we increased our threshold of amyloid positivity to having "low levels" of amyloid based on K-means clustering of baseline PIB levels into low and high groups (low or no PIB $<1.30$ PIB DVR; see Materials and Methods; Fig. 1), a value that maps well onto the peak of the quadratic curve between baseline PIB levels and PIB slope. This allowed us to increase our sample size to include anyone on the ascending limb of the inverted $U$, but before rates start to decelerate after a 1.30 PIB DVR, suggesting a relatively later disease stage. Similar results were obtained from the stepwise regression analyses for those with $<1.30$ baseline PIB DVR levels, as was seen for those who were $\mathrm{PIB}^{-}$. If we include all participants in the same stepwise linear regression analysis, results are similar with the exception that baseline PIB level was a significant predictor of AV-1451 uptake in Braak stages I-II across all participants $\left(r_{(1,35)}=0.462, \beta=0.562, t=3.084, p=\right.$ $\left.0.004, r^{2}=0.214\right)$.

\section{Memory decline predicted by amyloid lags behind pathological changes}

To investigate the earliest effects of amyloid measures on memory decline, we performed a stepwise linear regression in $\mathrm{PIB}^{-}$ individuals with baseline PIB level, PIB slope, gray matter slope, $A P O E \varepsilon 4$ status, age, sex, and education as predictors of $\triangle$ Episodic Memory Composite. We found that no predictors satisfied model entry criteria. These results indicate that detectable $\mathrm{A} \beta$ aggregation is required to produce measureable episodic memory dysfunction, at least using standard memory tests. For visualization of regression results, correlations between baseline PIB levels and PIB slope with $\Delta$ Episodic Memory Composite in $\mathrm{PIB}^{-}$participants are shown in Figure 5, $A$ and $B$.

We next examined memory decline in participants with $<$ 1.30 PIB DVR (based on K-means clustering of participants with baseline PIB levels who are on the ascending limb of the inverted $\mathrm{U})$. A stepwise linear regression (with the same predictors as above) showed that PIB slope was the best predictor of $\Delta$ Episodic
Memory Composite $\left(r_{(1,59)}=0.296, \beta=-1.595, t=-2.380\right.$, $\left.p=0.021, r^{2}=0.088\right)$. There were no significant interactions between PIB slope and PIB positivity. Thus, faster $\mathrm{A} \beta$ accumulation was associated with greater memory decline over time, suggesting that slightly more elevated $\mathrm{A} \beta$ levels is necessary to begin seeing change in memory. For visualization of regression results, correlations between baseline PIB levels and PIB slope with $\Delta$ Episodic Memory Composite in participants with $<1.30 \mathrm{PIB}$ DVR are shown in Figure 5, $C$ and $D$.

To confirm that higher amyloid levels are also associated with memory decline, we conducted stepwise linear regression in all participants (with the same predictors as above), which resulted in two significant models. Model 1 included baseline PIB level as the best predictor of $\Delta$ Episodic Memory Composite $\left(r_{(1,69)}=\right.$ 0.393, $\left.\beta=-0.206, t=-3.55, p=0.001, r^{2}=0.154\right)$. Model 2 included baseline PIB levels $\left(r_{(2,68)}=0.489, \beta=-0.178, t=\right.$ $-3.14, p=0.002)$ and gray matter slope $\left(\beta=4.4 \mathrm{e}^{-6}, t=2.75\right.$, $\left.p=0.008, \Delta r^{2}=0.084\right)$ as the best predictors of memory decline. There were no significant interactions between PIB slope and PIB positivity. Thus, at higher levels of $\mathrm{A} \beta$, baseline $\mathrm{PIB}$ level alone is predictive of memory decline as is the slope of accumulation. For the visualization of regression results, correlations between baseline PIB level and PIB slope with $\Delta$ Episodic Memory Composite in all participants are shown in Figure 5, E and $F$.

\section{Discussion}

Overall, these results indicate that very low levels of brain $\mathrm{A} \beta$ predict the subsequent development of tau pathology over a period of about 5 years in neocortical brain regions that characterize tau deposition in $\mathrm{AD}$. While multivariate models show that the rate of $\mathrm{A} \beta$ deposition is most predictive of subsequent tau, even baseline subthreshold levels of A $\beta$ predict tau deposition. Memory decline, however, was seen in association with higher levels of $\mathrm{A} \beta$ and could be predicted by baseline PIB measurements in those individuals with the highest levels, and by faster accumulation (i.e., higher slopes) in those with low PIB levels. This suggests that memory impairment develops after $\mathrm{AD}$ pathology has begun to spread. Together, these results indicate that $\mathrm{AD}$ is beginning in those who are nominally "amyloid negative," and by the time high levels of brain $A \beta$ eventuate, the rate of accumulation is already slowing.

Previous findings from longitudinal $\mathrm{A} \beta$ imaging have shown a quadratic relationship between baseline $\mathrm{A} \beta$ deposition and $\mathrm{A} \beta$ accumulation across mixed groups, including healthy control subjects and individuals with mild cognitive impairment and $\mathrm{AD}$ (Villain et al., 2012; Jack et al., 2013b; Villemagne et al., 2013). We found an inverted- $U$ relationship between baseline $A \beta$ level and $\mathrm{A} \beta$ accumulation in cognitively normal individuals, extending 

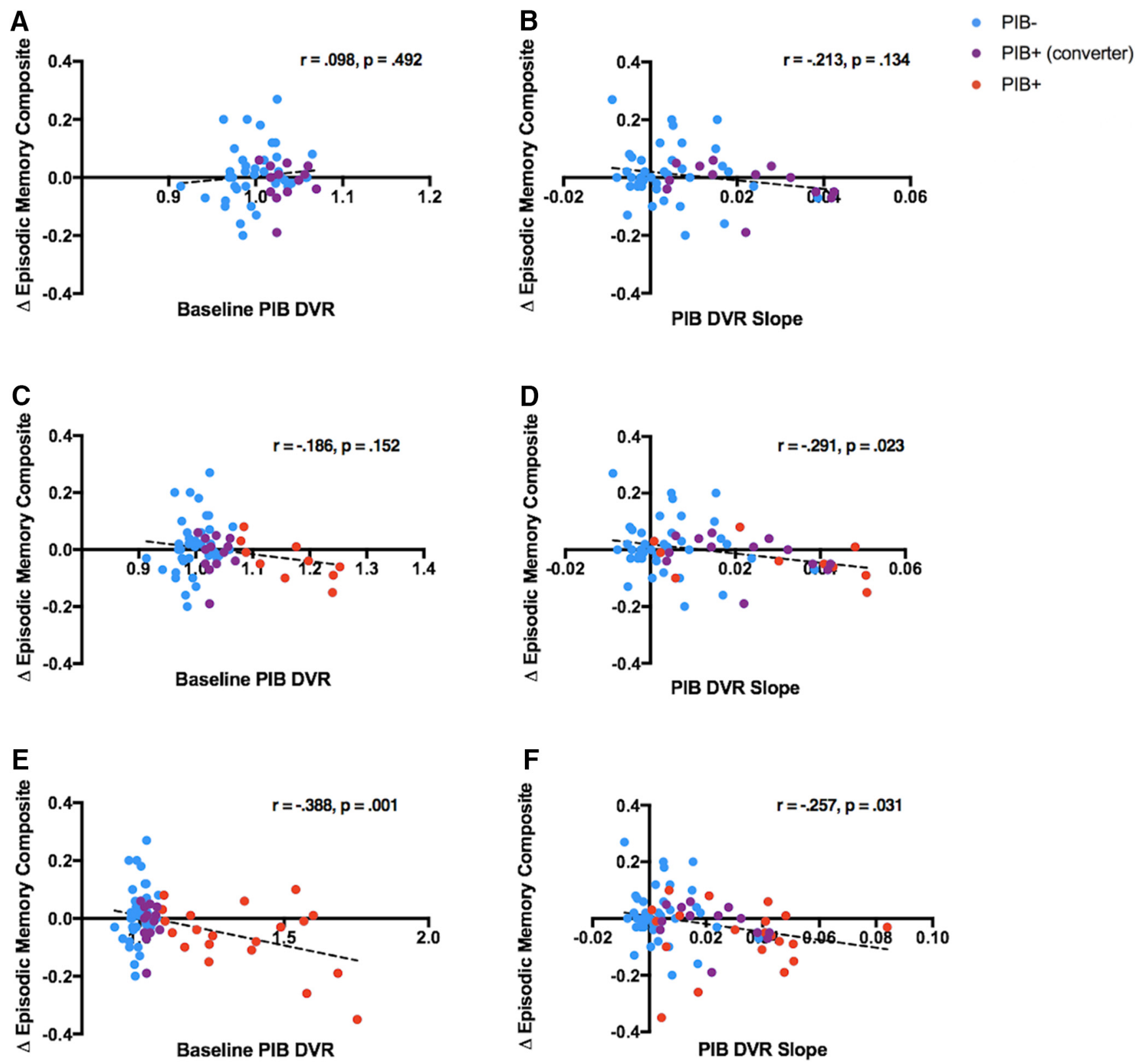

Figure 5. Relationship between PIB measures and change in episodic memory performance over time. Participants were identified as PIB ${ }^{-}(<1.07$ PIB DVR at all time points; $N=38 ;$ blue),

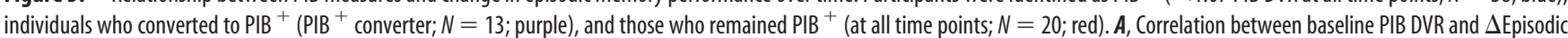
Memory Composite in PIB ${ }^{-}$participants $(N=51)$. B, Correlation between PIB DVR slope and $\Delta$ Episodic Memory Composite in PIB ${ }^{-}$participants. C, Correlation between baseline PIB DVR and $\Delta$ Episodic Memory Composite in PIB participants with a $<1.30$ baseline value $(N=61)$. $\boldsymbol{D}$, Correlation between PIB DVR slope and $\Delta$ Episodic Memory Composite in PIB participants with a $<1.30$ baseline value. $\boldsymbol{E}$, Correlation between baseline PIB DVR and $\Delta$ Episodic Memory Composite in all participants $(N=71)$. $\boldsymbol{F}$, Correlation between PIB DVR slope and $\Delta$ Episodic Memory Composite in all participants.

previous findings in more heterogeneous samples (Jack et al., 2013b; Villemagne et al., 2013). The strong evidence we present for a quadratic function between baseline PIB levels and PIB slope may result from using DVR values, which are more stable and less likely to be affected by changes in perfusion that occur with disease progression than the more commonly used SUVR values (van Berckel et al., 2013; Cselényi and Farde, 2015). A $\beta$ accumulation may slow with greater $A \beta$ deposition as a result of (1) poor detection of a change in $A \beta$ accumulation at high levels of $A \beta$, possibly due to PET measurements reaching a ceiling or changes in the availability of binding sites; (2) increasing the clearance of $A \beta$; (3) cortical atrophy resulting in reduced tracer measures; or (4) diminishing synaptic activity, since $A \beta$ is regu- lated by synaptic activity. Our finding of slowing $A \beta$ deposition suggests that high $A \beta$ levels even in asymptomatic people may reflect a relatively late stage of preclinical $\mathrm{AD}$. This is also consistent with the observation that these individuals show the greatest memory decline. It is worth noting that the peak of the inverted $\mathrm{U}$ occurs at a PIB DVR of 1.30 , identical to the value that differentiated high and low PIB groups in the cluster analysis. This corresponds to a value of 43 centiloids (Klunk et al., 2015), representing a moderate increase in tracer binding that is consistent with the interpretation that amyloid accumulation slows well before peak levels are reached.

Across all participants, including those with high $\mathrm{A} \beta$ levels, the baseline $A \beta$ level was the best predictor of subsequent tau deposition in Braak stage I-II regions. This is analogous to the 
relationship between baseline $A \beta$ level and memory, and is consistent with the likelihood that $\mathrm{A} \beta$ exerts its effects on memory through medial temporal lobe tau deposition (Maass et al., 2017). However, the rate of $\mathrm{A} \beta$ accumulation was the best predictor of subsequent tau deposition in Braak stage III-VI regions regardless of baseline $A \beta$ level, demonstrating that tau deposition is increased with higher levels of $A \beta$ and more rapidly accumulating $\mathrm{A} \beta$ even at very low levels of amyloid accumulation. These results are consistent with those of a previous study that reported a relationship between the rate of $A \beta$ change and tau deposition (Tosun et al., 2017), indicating that faster $A \beta$ accumulation in parietotemporal brain regions was associated with more tau deposition in inferior temporoparietal cortex. It is important to note that the level of AV-1451 uptake in Braak stages V-VI is still quite low and does not suggest that these individuals would be classified as being in Braak stages V-VI, but rather that tau is beginning to deposit in widespread neocortical areas even in normal people who are amyloid negative (Lowe et al., 2018). No participants met the criteria for being in Braak stages V-VI, but five met the criteria for Braak stages III-IV. This finding is interesting when put into the context of the postmortem pathology literature, which has proposed that $\mathrm{A} \beta$ accumulation may trigger tau to begin depositing in Braak stages III-IV, initiating a vicious cycle of A $\beta$ and tau spread (Price and Morris, 1999; Bloom, 2014).

Further, despite the finding that the rate of $A \beta$ accumulation was more informative than baseline values in multivariate models, baseline $A \beta$ measurements did in fact predict the ultimate amount of tau in Braak stages III-IV ROIs in bivariate correlations as well as stepwise linear regression models. This is a surprising finding given that the baseline PIB DVRs in the $\mathrm{PIB}^{-}$ group of participants were all below the very low threshold of 1.07. It is consistent with our overall findings that even those who do not meet the formal criteria for preclinical AD may be depositing $\mathrm{A} \beta$ to a significant degree, and variability in $\mathrm{A} \beta$ measures even at very low levels is informative. Furthermore, although tau deposition is very low in Braak stages III-VI regions in normal subjects, the relationship to $\mathrm{A} \beta$ suggests that this deposition may be pathologic.

There are several methodological features of the study design that deserve discussion. First, both nonaccumulators and accumulators were included in all analyses. Negative slopes are not likely indicative of amyloid clearance, but probably reflect measurement error since they particularly occur in those with very low baseline DVRs. Rather than exclude such individuals, their data can still contribute meaningful information to the regression models. When we removed them from the analyses, results did not significantly change; thus, we opted to include them to increase our power. Second, we find robust results even with a relatively small sample size. The pattern of associations among baseline PIB levels, PIB slope, and AV-1451 accumulation is repeatedly seen across all brain regions, increasing confidence in the overall pattern of results.

When determining which $\mathrm{A} \beta$ measures best predict memory decline, our findings suggest several major points. First, when baseline $A \beta$ levels are high, $A \beta$ is the strongest predictor of memory decline (Fig. $5 E, F$ ). However, presumably because those with the highest baseline $A \beta$ level show slower rates of $A \beta$ accumulation, the rate of change of $A \beta$ becomes less informative about disease status when individuals reach high levels of brain $A \beta$, reflecting a later stage of preclinical $\mathrm{AD}$. Second, when baseline $\mathrm{A} \beta$ levels are lower (or intermediate), $\mathrm{A} \beta$ accumulation is the strongest predictor of memory decline, likely because such individuals are on the ascending limb of the inverted $U$ described in
Figure 2, when rates of change may be more important than absolute levels. Finally, in those who are amyloid negative, the effect of $A \beta$ on memory decline, in contrast to the effects on tau, has yet to become evident. In such individuals, the relationship between the rate of change in $A \beta$ levels and memory decline is marginal and becomes significant when the threshold is slightly higher, suggesting that memory decline appears to lag behind tau deposition in response to increasing levels of $\mathrm{A} \beta$. Together, these data support a proposed mechanistic model of $\mathrm{AD}$ pathogenesis in which $\mathrm{A} \beta$ precedes tau, and both precede memory decline (Jack et al., 2013a).

Together, these findings have important implications for the development of therapeutic trials in preclinical AD (Sperling et al., 2011a). Our data indicate that $\mathrm{A} \beta$ measures predict tau deposition well before symptoms manifest and in those who are below a threshold. Memory decline seems to lag behind the effects of amyloid and tau, supporting the approach in which reliance on memory loss as a selection criterion for clinical trial participants would represent a relatively late stage in the $\mathrm{AD}$ continuum. While the rate of $A \beta$ accumulation is informative in predicting those in whom tau will deposit and amnesia will develop, longitudinal measurement of $\mathrm{A} \beta$ may be impractical for selecting participants for therapeutic trials, although the ability to observe amyloid accumulation over time in potential study participants would likely improve very early detection of pathology. However, the inverted- $\mathrm{U}$ relationship between baseline $\mathrm{A} \beta$ levels and $\mathrm{A} \beta$ deposition indicates that intervention on the "upslope" of this inverted $\mathrm{U}$, including subjects with low and negative $\mathrm{A} \beta$ measurements, below a centiloid value of 43 , might be the optimal approach. Thus, based on these data we would predict that individuals on the "higher" end of $A \beta^{-}$and on the "lower" end of $A \beta^{+}$ would be the most likely to benefit from an amyloid-lowering therapy. Future examination of larger cohorts with longitudinal study and the more widely available F-18 amyloid imaging agents should help to establish realistic thresholds and statistical models for such interventions.

\section{References}

Baker SL, Lockhart SN, Price JC, He M, Huesman RH, Schonhaut D, Faria J, Rabinovici G, Jagust WJ (2017) Reference tissue-based kinetic evaluation of 18F-AV-1451 in aging and dementia. J Nucl Med 58:332-338. CrossRef Medline

Bateman RJ, Xiong C, Benzinger TL, Fagan AM, Goate A, Fox NC, Marcus DS, Cairns NJ, Xie X, Blazey TM, Holtzman DM, Santacruz A, Buckles V, Oliver A, Moulder K, Aisen PS, Ghetti B, Klunk WE, McDade E, Martins $\mathrm{RN}$, et al (2012) Clinical and biomarker changes in dominantly inherited Alzheimer's Disease. N Engl J Med 367:795-804. CrossRef Medline

Bloom GS (2014) Amyloid- $\beta$ and tau: the trigger and bullet in Alzheimer disease pathogenesis. JAMA Neurol 71:505-508. CrossRef Medline

Braak H, Braak E (1997) Frequency of stages of Alzheimer-related lesions in different age categories. Neurobiol Aging 18:351-357. CrossRef Medline

Cselényi Z, Farde L (2015) Quantification of Blood flow-dependent component in estimates of beta-amyloid load obtained using quasi-steady-state standardized uptake value ratio. J Cereb Blood Flow Metab 35:1485-1493. CrossRef Medline

Desikan RS, Ségonne F, Fischl B, Quinn BT, Dickerson BC, Blacker D, Buckner RL, Dale AM, Maguire RP, Hyman BT, Albert MS, Killiany RJ (2006) An automated labeling system for subdividing the human cerebral cortex on MRI scans into gyral based regions of interest. Neuroimage 31:968980. CrossRef Medline

Donohue MC, Sperling RA, Petersen R, Sun CK, Weiner MW, Aisen PS (2017) Association between elevated brain amyloid and subsequent cognitive decline among cognitively normal persons. JAMA 317:2305-2316. CrossRef Medline

Drachman DA (2014) The amyloid hypothesis, time to move on: amyloid is the downstream result, not cause, of Alzheimer's disease. Alzheimers Dement 10:372-380. CrossRef Medline 
Jack CR Jr, Knopman DS, Jagust WJ, Petersen RC, Weiner MW, Aisen PS, Shaw LM, Vemuri P, Wiste HJ, Weigand SD, Lesnick TG, Pankratz VS, Donohue MC, Trojanowski JQ (2013a) Tracking pathophysiological processes in Alzheimer's disease: an updated hypothetical model of dynamic biomarkers. Lancet Neurol 12:207-216. CrossRef Medline

Jack CR Jr, Wiste HJ, Lesnick TG, Weigand SD, Knopman DS, Vemuri P, Pankratz VS, Senjem ML, Gunter JL, Mielke MM, Lowe VJ, Boeve BF, Petersen RC (2013b) Brain $\beta$-amyloid load approaches a plateau. Neurology 80:890-896. CrossRef Medline

Klunk WE, Koeppe RA, Price JC, Benzinger TL, Devous MD Sr, Jagust WJ, Johnson KA, Mathis CA, Minhas D, Pontecorvo MJ, Rowe CC, Skovronsky DM, Mintun MA (2015) The Centiloid Project: standardizing quantitative amyloid plaque estimation by PET. Alzheimers Dement 11:1-15.e4. CrossRef Medline

Leal SL, Landau SM, Bell RK, Jagust WJ (2017) Hippocampal activation is associated with longitudinal amyloid accumulation and cognitive decline. Elife 6:e22978. CrossRef Medline

Lowe VJ, Wiste HJ, Senjem ML, Weigand SD, Therneau TM, Boeve BF, Josephs KA, Fang P, Pandey MK, Murray ME, Kantarci K, Jones DT, Vemuri P, Graff-Radford J, Schwarz CG, Machulda MM, Mielke MM, Roberts RO, Knopman DS, Petersen RC, et al (2018) Widespread brain tau and its association with ageing, Braak stage and Alzheimer's dementia. Brain 141:271-287. CrossRef Medline

Maass A, Landau S, Baker SL, Horng A, Lockhart SN, La Joie R, Rabinovici GD, Jagust WJ (2017) Comparison of multiple tau-PET measures as biomarkers in aging and Alzheimer's disease. Neuroimage 157:448-463. CrossRef Medline

Marks SM, Lockhart SN, Baker SL, Jagust WJ (2017) Tau and $\beta$-amyloid are associated with medial temporal lobe structure, function and memory encoding in normal aging. J Neurosci 37:3192-3201. CrossRef Medline

Mirra SS, Heyman A, McKeel D, Sumi SM, Crain BJ, Brownlee LM, Vogel FS, Hughes JP, van Belle G, Berg L (1991) The Consortium to Establish a Registry for Alzheimer's Disease (CERAD). Part II. Standardization of the neuropathologic assessment of Alzheimer's disease. Neurology 41:479486. CrossRef Medline

Mormino EC, Kluth JT, Madison CM, Rabinovici GD, Baker SL, Miller BL, Koeppe RA, Mathis CA, Weiner MW, Jagust WJ (2009) Episodic memory loss is related to hippocampal-mediated beta-amyloid deposition in elderly subjects. Brain 132:1310-1323. CrossRef Medline

Mormino EC, Brandel MG, Madison CM, Marks S, Baker SL, Jagust WJ (2012) $\mathrm{A} \beta$ Deposition in aging is associated with increases in brain activation during successful memory encoding. Cereb Cortex 22:1813-1823. CrossRef Medline

Mullard A (2012) Sting of Alzheimer's failures offset by upcoming prevention trials. Nat Rev Drug Discov 11:657-660. CrossRef Medline

Ossenkoppele R, Schonhaut DR, Schöll M, Lockhart SN, Ayakta N, Baker SL, O’Neil JP, Janabi M, Lazaris A, Cantwell A, Vogel J, Santos M, Miller ZA, Bettcher BM, Vossel KA, Kramer JH, Gorno-Tempini ML, Miller BL, Jagust WJ, Rabinovici GD (2016) Tau PET patterns mirror clinical and neuroanatomical variability in Alzheimer's disease. Brain 139:1551-1567. CrossRef Medline

Pascoal TA, Mathotaarachchi S, Shin M, Benedet AL, Mohades S, Wang S, Beaudry T, Kang MS, Soucy JP, Labbe A, Gauthier S, Rosa-Neto P (2017) Synergistic interaction between amyloid and tau predicts the progression to dementia. Alzheimers Dement 13:644-653. CrossRef Medline

Price JL, Morris JC (1999) Tangles and plaques in nondemented aging and "preclinical" alzheimer's disease. Ann Neurol 45:358-368. CrossRef Medline

Rousset OG, Ma Y, Evans AC (1998) Correction for partial volume effects in PET: principle and validation. J Nucl Med 39:904-911. Medline

Schöll M, Lockhart SN, Schonhaut DR, O’Neil JP, Janabi M, Ossenkoppele R, Baker SL, Vogel JW, Faria J, Schwimmer HD, Rabinovici GD, Jagust WJ
(2016) PET imaging of tau deposition in the aging human brain. Neuron 89:971-982. CrossRef Medline

Shcherbinin S, Schwarz AJ, Joshi A, Navitsky M, Flitter M, Shankle WR, Devous MD Sr, Mintun MA (2016) Kinetics of the tau PET tracer 18FAV-1451 (T807) in subjects with normal cognitive function, mild cognitive impairment, and Alzheimer disease. J Nucl Med 57:1535-1542. CrossRef Medline

Sperling RA, Aisen PS, Beckett LA, Bennett DA, Craft S, Fagan AM, Iwatsubo T, Jack CR Jr, Kaye J, Montine TJ, Park DC, Reiman EM, Rowe CC, Siemers E, Stern Y, Yaffe K, Carrillo MC, Thies B, Morrison-Bogorad M, Wagster MV, et al (2011a) Toward defining the preclinical stages of Alzheimer's disease: recommendations from the National Institute on Aging-Alzheimer's Association workgroups on diagnostic guidelines for Alzheimer's disease. Alzheimers Dement 7:280-292. CrossRef Medline

Sperling RA, Jack CR Jr, Aisen PS (2011b) Testing the right target and right drug at the right stage. Sci Transl Med 3:111 cm33. CrossRef Medline

Sperling RA, Rentz DM, Johnson KA, Karlawish J, Donohue M, Salmon DP, Aisen P (2014) The A4 study: stopping AD before symptoms begin? Sci Transl Med 6:228fs13. CrossRef Medline

Thal DR, Rüb U, Schultz C, Sassin I, Ghebremedhin E, Del Tredici K, Braak E, Braak H (2000) Sequence of Abeta-protein deposition in the human medial temporal lobe. J Neuropathol Exp Neurol 59:733-748. CrossRef Medline

Thal DR, Rüb U, Orantes M, Braak H (2002) Phases of A beta-deposition in the human brain and its relevance for the development of AD. Neurology 58:1791-1800. CrossRef Medline

Tosun D, Landau S, Aisen PS, Petersen RC, Mintun M, Jagust W, Weiner MW (2017) Association between tau deposition and antecedent amyloid- $\beta$ accumulation rates in normal and early symptomatic individuals. Brain 140:1499-1512. CrossRef Medline

van Berckel BN, Ossenkoppele R, Tolboom N, Yaqub M, Foster-Dingley JC, Windhorst AD, Scheltens P, Lammertsma AA, Boellaard R (2013) Longitudinal amyloid imaging using 11C-PiB: methodologic considerations. J Nucl Med 54:1570-1576. CrossRef Medline

Villain N, Chételat G, Grassiot B, Bourgeat P, Jones G, Ellis KA, Ames D, Martins RN, Eustache F, Salvado O, Masters CL, Rowe CC, Villemagne VL (2012) Regional dynamics of amyloid- $\beta$ deposition in healthy elderly, mild cognitive impairment and Alzheimer's disease: a voxelwise PiB-PET longitudinal study. Brain 135:2126-2139. CrossRef Medline

Villemagne VL, Burnham S, Bourgeat P, Brown B, Ellis KA, Salvado O, Szoeke C, Macaulay SL, Martins R, Maruff P, Ames D, Rowe CC, Masters CL (2013) Amyloid $\beta$ deposition, neurodegeneration, and cognitive decline in sporadic Alzheimer's disease: a prospective cohort study. Lancet Neurol 12:357-367. CrossRef Medline

Villeneuve S, Rabinovici GD, Cohn-Sheehy BI, Madison C, Ayakta N, Ghosh PM, La Joie R, Arthur-Bentil SK, Vogel JW, Marks SM, Lehmann M, Rosen HJ, Reed B, Olichney J, Boxer AL, Miller BL, Borys E, Jin LW, Huang EJ, Grinberg LT, et al (2015) Existing Pittsburgh Compound-B positron emission tomography thresholds are too high: statistical and pathological evaluation. Brain 138:2020-2033. CrossRef Medline

Vos SJ, Xiong C, Visser PJ, Jasielec MS, Hassenstab J, Grant EA, Cairns NJ, Morris JC, Holtzman DM, Fagan AM (2013) Preclinical Alzheimer's disease and its outcome: a longitudinal cohort study. Lancet Neurol 12: 957-965. CrossRef Medline

Welsh KA, Butters N, Hughes JP, Mohs RC, Heyman A (1992) Detection and staging of dementia in Alzheimer's disease. Use of the neuropsychological measures developed for the Consortium to Establish a Registry for Alzheimer's Disease. Arch Neurol 49:448-452. CrossRef Medline

Wooten D, Guehl NJ, Verwer EE, Shoup TM, Yokell DL, Zubcevik N, Vasdev N, Zafonte RD, Johnson KA, Fakhri G El, Normandin MD (2017) Pharmacokinetic evaluation of the tau PET radiotracer [18F]T807 ([18F]AV1451) in human subjects. J Nucl Med 58:484-491. CrossRef Medline 